\title{
Prática da mobilidade tecnológico-educacional, um ensaio sobre a definição do conceito
}

\author{
Gílian Cristina Barros ${ }^{1}$, Glaucia da Silva Brito ${ }^{1}$ \\ ${ }^{1}$ Grupo de Estudos Professor, Escola e Novas Tecnologias (GEPETE) - Universidade \\ Federal do Paraná (UFPR) - Curitiba - PR - Brazil \\ \{gilian@ufpr.br,glaucia@ufpr.br\}
}

\begin{abstract}
This bibliographical essay emerges from the pilot project One Laptop per Child (OLPC) in the state of Paraná and presents the journey of the construction of the concept of 'practice of mobility technological-educational' which is being deepened from the effort of study and doctoral research Education in the line of Culture, Education and School of the Paraná University of Paraná. This pedagogical practice considers the triad: teacher-studentcontent. And has five dimensions: the space/time, the mind (thought), the curriculum content and political-economic.
\end{abstract}

Resumo. Este ensaio bibliográfico emerge da formação de professores no projeto piloto Um Computador por Aluno (UCA) no estado do Paraná e apresenta o caminhar da construção do conceito de prática da mobilidade tecnológico-educacional que vem sendo aprofundado a partir do esforço de estudo e pesquisa de doutorado em Educação na linha de Cultura, Escola e Ensino da Universidade Paraná do Paraná. Compreende-se até aqui que essa prática pedagógica considera a mobilidade do trinômio professor-alunoconteúdo. Possui cinco dimensões: a fisico/espacial, a temporal, a mental (de pensamento), a dos conteúdos curriculares e a político-econômica.

\section{Introdução}

Gestos, sons guturais, sinais de fumaça, estrondo de tambores e o homem a distância e em movimento se comunicando, trocando mensagens entre si ou buscando contato com deuses que poderiam lhe auxiliar.

Seja numa perspectiva evolucionista ou criacionista, ocidental ou oriental de leitura e compreensão do mundo os homens sempre estiveram em movimento procurando se comunicar. Essa necessidade de se comunicar em movimento é revelada nas cartas que Paulo enviou aos novos conversos de Éfeso, Tessalônica e Corinto, por exemplo; ou quando o povo erguia altares para conectar-se com Deus; ou por meio de mantras cantados em solo ou em grupo que levam as petições e agradecimentos a alguém; ou também, por sinais de fumaça que chegam com cheiro suave aos céus, ultrapassando as nuvens, vindo de fragrâncias que sobem de velas e incensos.

Pode-se afirmar, mesmo empiricamente, que o homem buscou formas de se comunicar, primeiramente, pela técnica e, posteriormente, pela ampliação da técnica na 
criação de $\operatorname{artefatos}^{1}$ que atendessem suas necessidades de transmitir mensagens, ou seja, se comunicar e estar em movimento, tal qual um nômade. Inicialmente, utilizando técnicas que faziam de seu próprio corpo um artefato de comunicação e depois, aprimorando suas descobertas e criações em artefatos móveis para comunicação.

Sendo assim, compreende-se que a discussão sobre o ato de se comunicar em movimento não é algo novo. [Lemos 2009 p.28] afirma que

\begin{abstract}
A mobilidade é inerente ao homem, sendo correlata à necessidade de criar um lugar no mundo, de construir para habitar" (Heidegger, 1958), de estabelecer um topus que nos proteja da solidão e do vazio do espaço genérico e abstrato. A cultura da mobilidade entrelaça questões tecnológicas, sociais, antropológicas. Para a comunicação, a mobilidade é central já que comunicar é fazer mover signos, mensagens, informações, sendo toda mídia (dispositivos, ambientes e processos) estratégias para transportar mensagens afetando nossa relação com o espaço e o tempo.
\end{abstract}

Diante do cenário apresentado até aqui e da fala anterior de [Lemos 2009] pode-se compreender que a utilização de dispositivos móveis ou gadgets (dispositivos eletrônicos) na educação traz consigo necessidades que são inerentes ao homem: a de se mover e a de se comunicar. Mas, vale também ressaltar que essas necessidades trazem consigo outro imperativo, o de se repensar as relações de espaço e tempo que se estabelecem na escola com a disponibilização, para alunos e professores, de dispositivos móveis.

\title{
1.1. O método, o problema: de onde emerge esse ensaio
}

Discussões e pesquisas desenvolvidas no Grupo da Universidade Paraná do Paraná responsável pela formação, realizada de 2010 a 2012, dos professores das escolas do projeto piloto 'Um Computador por Aluno - UCA' no Paraná levaram a esse repensar necessário: o repensar das relações de espaço e de tempo que se estabelecem na escola com a chegada de dispositivos móveis para uso de professores e de alunos. E, é nesse contexto que emerge o conceito de 'mobilidade tecnológico-educacional' no trinômio professor-aluno-conteúdo.

A definição, a análise e o aprofundamento desse conceito se constituem desafio, mesmo após a conclusão da formação dos professores das escolas do projeto piloto, pois os pesquisadores envolvidos nessa discussão têm realizado estudos que buscam maturar a construção do conceito 'mobilidade tecnológico-educacional' em outros contextos de formação de professores para e com o uso de dispositivos móveis, como vemos em: [Marczal e Direne 2012], [Barros et al. 2012] e [Direne et al. 2012]

Este artigo é um ensaio bibliográfico que busca definir o conceito de 'prática da mobilidade tecnológico-educacional' subjacente da situação apresentada nos dois parágrafos anteriores, mas que tem sido aprofundado a partir do esforço de estudo e pesquisa de doutorado, potencializado pelos referenciais teóricos abordados no Programa de Pós-Graduação em Educação da Universidade Paraná do Paraná, na linha de Cultura, Escola e Ensino.

\footnotetext{
${ }^{1}$ Entende-se artefato qualquer objeto feito, modificado e utilizado pelo ser humano.
} 


\section{A mobilidade na educação}

Fundamentando o estudo inicial sobre o uso de dispositivos móveis, como: celular, smartphone, tablet e laptops em educação, verificaram-se as obras de [Sharples et al. 2005] e [Sharples 2003] que abordam aspectos da aprendizagem móvel, mobile learning, m-learning.

[Sharples et al. 2005] teorizam sobre a organização de um modelo de aprendizagem em espaços formais e não formais como apoio à aprendizagem móvel. $\mathrm{E}$ com vistas a evitar os ruídos que o excesso de recursos acessados por alunos em dispositivos móveis podem causar, [Sharples 2003] a partir de um recurso que combina as funções de computador, telefone móvel e câmera digital, verifica os benefícios que este pode trazer para as aprendizagens dos alunos, bem como relata que professores detectaram as possibilidades de gerenciamento das aprendizagens dos alunos fora do espaço escolar e de construção de atividades com objetivos de ensino.

Outros referenciais também foram consultados com o intuito de compreender as discussões que vigoram sobre o uso de dispositivos móveis em educação, desses destacam-se: [Graziola 2009] que verifica como as tecnologias móveis sem fio (TMSF) podem contribuir para práticas do professor em sala de aula numa perspectiva dialógica, colaborativa e cooperativa; [Brito e Mateus 2011] que discutem sobre a presença cada vez mais constante de celulares, smartphones e tablets em sala de aula e suas contribuições para a aprendizagem dos alunos; [Santaella 2010] indaga sobre o acesso livre e ubíquo ${ }^{2}$ ao conhecimento, ou seja, questiona: àquilo que podemos chamar de aprendizagem ubíqua, tem poderes para substituir a educação formal?; e [Schelmmer et al. 2007] que apresentam vinte e cinco casos detectados a partir de estudo exploratório sobre práticas de m-learning no contexto brasileiro que vem sendo aplicadas de forma experimental no meio acadêmico.

Do estudo de [Schelmmer et al. 2007], vale ressaltar os desafios apresentados para desenvolvimento e aplicação do que os autores chamam de Tecnologias Digitais Emergentes - TDEs, tais como as TMSF, que são: de "ordem contextual/social", referente as resistências e a necessidade de desenvolvimento de cultura para o uso; de "ordem didáticopedagógico", alusiva a necessidade de inovação nas práticas didático-pedagógicas e de processos de formação de professores para o uso e; de ordem "tecnológica e econômica".

Considerando os desafios para desenvolvimento e aplicação de dispositivos móveis no meio acadêmico, apresentados por [Schelmmer et al. 2007], o conceito de 'prática da mobilidade tecnológico-educacional' surge no campo do desafio de ordem didático-pedagógico, mesmo sendo necessário compreender que este conceito está matizado pelos demais desafios apresentados e por outros tantos que surjam no decorrer da prática pedagógica.

\footnotetext{
2 Do latim, ubiquu, capacidade de estar conectado à rede e fazer uso da conexão a todo o momento, que está ao mesmo tempo em toda a parte, onipresente. (WIKIPEDIA).
} 


\section{A prática da mobilidade tecnológico-educacional}

\subsection{Prática pedagógica e mobilidade}

Uma das indagações que surgiu na atuação de uma das autoras desse ensaio na formação de professores para o uso de dispositivos móveis, foi: Por que parece ser tão difícil para alguns professores pensar atividades de ensino com dispositivos móveis que levem ao movimento físico, espacial, no qual os alunos trabalhem mesmo que no espaço de sala de aula, fora de suas carteiras, em grupos e não apenas individualmente?

Ao ler [Vincent et al. 2001] conclui-se que esse "não mover-se fisicamente" tem relação intrínseca com a história e teoria da forma escolar que como determinação sóciohistórica apresenta um modelo no qual as atividades de ensino atendem a essas determinações. Sendo assim, mover-se fisicamente seria ir contra ao modelo construído social e historicamente. Entretanto, [Schmidt and Garcia 2008], afirmam que

A escola não é somente um lugar de reprodução, mas também de criação, de produção de si própria, por que entende que esta tem a capacidade de autodefinir e, portanto, de se transformar, da mesma forma que a sociedade humana dispõe de uma capacidade de criação simbólica, graças à qual se constroem e se produzem seus sentidos, bem como, seu sistema de orientação de condutas.

A escola, mesmo sendo, uma "instituição de um tipo muito particular", como lê-se em [Nóvoa 1998], "que não pode ser pensada como uma fábrica ou oficina qualquer", também não pode estar alheia ao que ocorre na sociedade, ao encadeamento geral da sociedade. Sendo assim, não pode ficar desatenta, por exemplo, ao uso de dispositivos móveis na educação, como o proposto neste ensaio, até porque este movimento tem invadido as salas de aula por meio de ações governamentais como as do Projeto UCA já citado e recentemente com a de distribuição de tablets aos professores como verifica-se em notícias ${ }^{3}$ na internet.

Assim, ao considerar a escola como um "mundo social", como lê-se em [Forquin 1993 p.167], "com características de vida próprias, seus ritmos e seus ritos, sua linguagem, seu imaginário, seus modos próprios de regulação e de transgressão, seu regime próprio de produção e de gestão de símbolos", pode-se vislumbrar nas possibilidades de transgressão e de criação, tal qual na sociedade humana, uma autodefinição, uma possibilidade de transformação de sua forma e de suas práticas. Uma vez que segundo [Veiga 1996]

... a prática pedagógica é uma prática social orientada por objetivos, finalidades e conhecimentos, e inserida no contexto da prática social. A prática pedagógica é uma dimensão da prática social. [p. 16]

O ensino é uma prática social concreta, dinâmica, multidimensional, interativa, sempre inédita e imprevisível. É um processo complexo que sofre influência de aspectos econômicos, psicológicos, técnicos, culturais, éticos, políticos, afetivos e estéticos. [p. 79]

\footnotetext{
${ }^{3}$ Disponíbilizado em, 09/10/2012 | 18:37 - goo.gl/6sIIW
} 
Desse modo, entende-se que a forma escolar determina as práticas pedagógicas, bem como por ela também é determinada. A prática pedagógica do professor em sala de aula revela reproduções e criações que são influenciadas por aspectos econômicos, psicológicos, técnicos, culturais, éticos, políticos, afetivos e estéticos, mesmo carregando consigo a ideia de conservação, pois prática é a repetição de ações no tempo e no espaço. Essas repetições possuem significado social e histórico para os que as praticam.

Do mesmo modo, cabe também afirmar que a prática pedagógica se enquadra no modelo social e histórico de sua época, no entanto, considerando que os indivíduos mudam a si mesmos por serem sociais e históricos, é possível que, consequentemente, suas práticas também sejam modificadas, e é essa intenção da proposição do conceito prática da mobilidade tecnológico-educacional.

\subsection{A prática da mobilidade tecnológico-educacional}

O termo mobilidade, geralmente, remete as possibilidades de movimento, seja quando trata do deslocamento geográfico - mobilidade urbana - seja na designação de mobilidade utilizada na física - propriedade dos móveis, da lei dos movimentos - ou seja, a mobilidade tecnológica - ligada à área da telecomunicação. Todas essas acepções subentendem mobilidade, movimento.

[...] são múltiplos os processos de mobilidade que se interconectam. [...] parece caber com justeza o termo "hipermobilidade" para caracterizá-los. Hipermobilidade porque à mobilidade física do cosmopolitismo crescente foi acrescida a mobilidade virtual das redes. Com os aparelhos móveis, ambas as mobilidades se entrelaçaram [...] para cujos usuários não faz mais sentido a expressão "entrar na internet", pois ela está sempre lá, na palma da mão [...]. [Santaella 2007 p.187]

E, todas essas formas de mobilidade: urbana, tecnológica, virtual, física e da física, chega às salas de aula corroborando para sua ampliação como diz [Pozo 2012 p.151]:

Quando as paredes das salas de aulas são ampliadas - porque a inovação afeta tanto os conteúdos como as metodologias e os espaços arquitetônicos -, quando é preciso aprender dentro e fora da escola, quando a contextualização do aprendizado vai além do tempo e do espaço e quando a colaboração é imprescindível, se tornam muito necessários certos meios que permitam aos alunos trabalhar em qualquer lugar onde estejam, no momento em que for possível e com os colegas de trabalho que escolherem, ainda que estes não estejam ao seu lado.

A mobilidade oportunizada pelos dispositivos móveis considerando o trinômio professor-aluno-conteúdo sugere movimento, movimento que envolve os espaços geográficos, as atividades de ensino realizadas, os conteúdos curriculares escolhidos, enfim tudo que permeia, o ensino e a aprendizagem na escola, e claro, os atores da escola ${ }^{4}$ : professores e alunos. Consequentemente, a mobilidade permite a ampliação das salas de aula, da escola.

\footnotetext{
${ }^{4}$ Atores da escola conseguem descontextualizar e recontextualizar as percepções das autoridades, tornando-as suas, por um processo de desconstrução e reconstrução do sentido em função da cultura local, de modo a sentirem-se atores do processo de mudança. [Gather Thuler 2001 p.90].
} 
Um aspecto importante que deve ser avaliado ao se organizar uma atividade que vise aprendizagens, utilizando dispositivos móveis, é que devemos partir do pressuposto de que os alunos, os professores e os conteúdos estão continuamente em movimento. Essa mobilidade no caso de professores e alunos é temporal, é físico/espacial e é de pensamento.

Por mobilidade temporal, entende-se a aprendizagem que ocorre para além dos tempos da escola e, como mobilidade físico/espacial, compreende-se a que ocorre para além dos espaços físicos tradicionais de aprendizagem na escola, visto que aprende-se ao longo do tempo, revisitando o conhecimento que foi adquirido anteriormente em momentos diferentes, e, mais amplamente, através de ideias e estratégias que configuramse em aprendizagens. Sendo assim, com o uso de tecnologias móveis sem fio, como laptop, celular, smartphone, alunos e professores, podem se mover de tema em tema no gerenciamento de projetos pessoais que potencialmente levam a aprendizagem de conteúdos curriculares. [Sharples et al. 2005] e [Sharples 2003]

Com a mobilidade pode-se compreender que as aprendizagens ocorrem para além da escola. As aprendizagens são gerenciadas nas transições da vida, sejam elas geográficas ou comunicacionais, pois as novas tecnologias são projetadas para suportar uma sociedade na qual as pessoas estão em movimento e cada vez mais tentando agregar a aprendizagem nos interstícios da vida cotidiana. [Sharples et al. 2005]

A mobilidade de pensamento ocorre a partir da teoria de reorganização do pensamento de [Tikhomirov 1981 p.13]. Ele afirma ter "dado especial atenção em mostrar como o computador muda a estrutura da atividade intelectual humana. A memória, o armazenamento da informação e suas buscas (ou reproduções) são reorganizadas". ${ }^{5}$

Os atos de ensinar e aprender se estabelecem num movimento no qual o pensamento pode ser amparado por tecnologias e por suas diferentes formas de armazenamento, organização e disponibilização das informações, alterando não só a percepção, manipulação e imaginação, mas as formas de interação com o mundo, como apresentado por [Lévy 1993 p.160]:

[...] tecnologias intelectuais desempenham um papel fundamental nos processos cognitivos, mesmo nos mais cotidianos; para perceber isto, basta pensar no lugar ocupado pela escrita nas sociedades desenvolvidas contemporâneas. Estas tecnologias estruturam profundamente nosso uso das capacidades de percepção, de manipulação e de imaginação.

Igualmente, ao que lê-se na citação anterior, a concepção de tecnologia compreendida neste ensaio, é a que se refere às tecnologias intelectuais. Pelas quais, [Lévy 1993 p.9] considera um campo no qual "não há informática em geral, nem essência congelada do computador, mas sim um campo de novas tecnologias intelectuais, aberto, conflituoso e parcialmente indeterminado."

Além do pensamento, os conteúdos também se movem. Vislumbra-se na prática da mobilidade tecnológico-educacional, além do movimento físico/espacial, temporal, e de pensamento, o movimento dos conteúdos curriculares. Uma vez, que os conteúdos curriculares não precisam mais estar organizados de forma linear em livros e manuais.

\footnotetext{
5 Tradução livre.
} 
A partir de [Williams apud Veiga Neto 1997], compreende-se os conteúdos curriculares como uma "porção da cultura" - em termos de conteúdos e práticas (de ensino, de avaliação, etc.) - que, por ser considerada relevante num dado momento histórico, é trazida para escola, ou seja, é escolarizada.

O digital oportuniza a organização rizomática e hipertextual dos conteúdos que agora se encontram nas nuvens ${ }^{6}$, ou seja, conteúdos que antes eram guardados no computador podem ser acessados de qualquer máquina ou dispositivo móvel, pois, não ficam disponibilizados num computador fixo, tipo de mesa, desktop, mas, em discos virtuais que podem ser acessados pela rede interna e/ou pela internet. [Barros et al. 2012]

E para a organização hipertextual desses conteúdos curriculares, que podem assumir inúmeras significações, há de se considerar a caracterização do hipertexto a partir de seis princípios destacados por [Lévy 1993 p. 24]: princípio de metamorfose ( extensão, composição e desenho permanentemente em jogo para os atores ${ }^{7}$ envolvidos); de heterogeneidade (nós e conexões heterogêneos: imagens, sons, palavras, diversas sensações, etc.); de multiplicidade e de encaixe das escalas (qualquer nó ou conexão, quando analisado, pode revelar-se como sendo composto por toda uma rede); de exterioridade (o crescimento e a diminuição, a composição e a recomposição permanente dependem de um exterior indeterminado); de topologia (a rede não está no espaço, ela é o espaço.); e de mobilidade de centros (possui permanentemente diversos centros que são como pontas luminosas perpetuamente móveis).

Deste modo, pondera-se até aqui, que a prática da mobilidade tecnológicoeducacional é aquela que considera a mobilidade do trinômio professor-aluno-conteúdo. Essa mobilidade ocorre quando professores, alunos e contéudos movem-se: os professores e os alunos, atores da escola, movem-se física/espacial, temporal e mentalmente (pensamento) e os conteúdos curriculares, movem-se quando são apresentados de forma hipertextual, preferencialmente, por meio de dispositivos móveis.

[Lemos 2009] ${ }^{8}$ quando trata da cultura da mobilidade apresenta "três dimensões fundamentais da mobilidade: o pensamento, a desterritorialização por excelência para Deleuze e Guattari (1980), a fisica (corpos, objetos, commoditites) e a informacionalvirtual (informação)". Ele, também afirma que:

Um tipo de mobilidade tem sempre impacto sobre outro. A mobilidade informacional-virtual tem impactos diretos sobre a mobilidade física e sobre o lugar e o espaço onde opera, e vice-versa. Não podemos dissociar comunicação, mobilidade, espaço e lugar. A comunicação é uma forma de "mover" informação de um lugar para outro, produzindo sentido, subjetividade, espacialização. [p.29]

Se um tipo de mobilidade causa impacto sobre o outro, como apresenta [Lemos 2009], é relevante considerar na 'prática da mobilidade tecnológico-educacional no

\footnotetext{
${ }^{6} \mathrm{O}$ conceito de computação em nuvem (em inglês, cloud computing) refere-se à utilização da memória e das capacidades de armazenamento e cálculo de computadores e servidores compartilhados e interligados por meio da Internet. [Wikipedia]

${ }^{7}$ Lévy considera atores: humanos, palavras, imagens, traços de imagens ou de contexto, objetos técnicos, componentes destes objetos, etc.

${ }^{8}$ Itálicos incluídos pelas autoras do ensaio.
} 
trinômio professor-aluno-conteúdo' as três dimensões por ele apresentadas: a física, a de pensamento e a do conteúdo (informação), uma vez que a comunicação é fator necessário para a educação. Sendo assim, com o ato de comunicar a educação oportuniza a produção de subjetividade e espacialização, porém e, sobretudo, a produção de sentido, de significado aos/dos conteúdos curriculares a serem ensinados e aprendidos.

Outro aspecto presente na fala de [Lemos 2009 p.29] sobre a cultura da mobilidade e que deve ser considerado na prática da mobilidade tecnológico-educacional é 'imobilidade'.

Os meios de transporte e de comunicação, incluindo aí os novos dispositivos móveis, implicam em mobilidades constrangidas por imobilidades infra-estruturais e dificuldades de acesso e de deslocamento. A mobilidade de uns se dá também em função da imobilidade de outros [...].

Este aspecto, o da imobilidade, causada por mobilidades constrangidas, como as infraestruturais, foi revelado na formação de professores das escolas do projeto piloto UCA no Paraná. A falta de infraestrutura lógica, de internet, foi um dos aspectos que causou grande desconforto, como se verifica nas falas ${ }^{9}$ de professores que participaram dessa formação, levando a novo questionamento: qual o papel do estado nesse contexto?

Prof. 01: Com a implantação do UCA em nossa escola muitas dificuldades surgiram e algumas foram superadas e outras ainda estão recebendo ajustes. Ainda não conseguimos conectar na internet 35 laptops ao mesmo tempo, a rede fica muito lenta e com apenas uma professora em sala, a ansiedade dos alunos acabou gerando indisciplina nos $5^{\circ}$ ano com quem trabalho.

Prof. 02: Com os alunos do $5^{\circ}$ ano, houve muita dificuldade para acessar a internet, a rede ficava muito lenta quando 35 laptops estavam ligados ao mesmo tempo.

Assim, uma nova dimensão se agrega a 'prática da mobilidade tecnológicoeducacional' a dimensão político-econômica, que influencia diretamente as outras dimensões, pois as determinações políticas e econômicas são decisivas, inclusive, no que se refere aos artefatos que chegam aos espaços escolares, considerando que nesse projeto a responsabilidade quanto a infraestrutura lógica e elétrica seria do estado.

\section{O que considerar finalmente}

Por que construir e compreender esse conceito, a prática da mobilidade tecnológicoeducacional? Essa construção faz-se necessária para apoiar o lócus no qual ele emergiu formação de professores das escolas do projeto piloto UCA no Paraná - mas, também para auxiliar outras iniciativas de formação ou de uso de dispositivos móveis na educação que surjam para além desse lócus. Esse ensaio pauta-se no exercício dessa prática ${ }^{10}$, a da

\footnotetext{
${ }^{9}$ Falas de professores participantes da formação, em outubro de 2012, no Ambiente MOODLE do Setor de Informática da Universidade Federal do Paraná.

${ }^{10}$ Entende-se prática como prática social.

Também aquela que se articula com a teoria. Essas duas dimensões: teoria e prática são integradas ao trabalho educativo. [RODRIGUES e KUENKER, 2007 p.58-59]
} 
mobilidade tecnológico-educacional, como complementar as demais práticas pedagógicas que o professor conhece e exercita.

Conclui-se que a 'prática da mobilidade tecnológico-educacional' é aquela na qual 'professores e alunos', atores da escola, 'movem pensamento' por meio do ensino e aprendizagem de 'conteúdos curriculares em diferentes tempos e espaços'. É aquela que permite, nos arranjos do ensino e da aprendizagem das porções da cultura, o movimento do pensamento que é reorganizado, potencialmente, pelo uso de dispositivos móveis, compreendidos aqui como tecnologias intelectuais. Os 'conteúdos curriculares estão em movimento' quando apresentados de forma rizomática, hipertextual, sendo que os movimentos do pensamento e do conteúdo podem ocorrer dentro e fora da sala de aula.

E, finalmente, todas essas dimensões: do pensamento, do conteúdo, do tempo, do espaço e a político-econômica, potencializadas pelo uso de dispositivos móveis em educação, poderão influenciar o exercício da prática da mobilidade tecnológicoeducacional no trinômio professor-aluno-conteúdo.

\section{Referências}

Barros, G.C.; Direne, A.; Kutzke, A. R. and Silva, W. da.. (2012) "A mobilidade tecnológico-educacional e as possibilidades de coincidência entre tecnologias e currículo por meio da produção e uso de webquests".In: III Seminário Web Currículo Educação e Mobilidade, São Paulo: PUCSP.goo.gl/h7Nox2. Agosto.

Brito, G. da S. and Mateus, M. de C. (2011) "Celulares, smartphones e tablets na sala de aula: complicações ou contribuições?” In: X Congresso Nacional de Educação EDUCERE, PUCPR. http://educere.bruc.com.br/CD2011/pdf/5943_3667.pdf, Agosto.

Direne, A.; Kutzke A; Marczal, D., Barros, G.; Bazzo, G.; Silva, F.; Silva, W. da; Peres, L. and Moura, L. (2012) "Aprofundamento da mobilidade tecnológico-educacional por meio de jogos intelectivos como facilitadores da comunicação professor-aluno em redes virtuais de ensino.” In: SBC. I Workshop de Desafios da Computação Aplicada a Educação. http://www.lbd.dcc.ufmg.br/bdbcomp/servlet/Trabalho?id=11450. Agosto.

Gather Thurler, M. (2001) Inovar no interior da escola. Porto Alegre: ArtMed.

Graziola, JR., P. Gaspar. (2009) Aprendizagem com mobilidade (M-Learning) nos processos de ensino e de aprendizagem: reflexões e possibilidades. Novas Tecnologias na Educação, páginas 1-10, CINTED.

Forquin, J.C. (1993) Escola e cultura: as bases sociais e epistemológicas do conhecimento escolar. Trad. Guacira Lopes Louro. Porto Alegre: Artes Médicas

Lemos, A. (2009) Cultura da mobilidade. Revista FAMECOS. Porto Alegre n. 40 dezembro.http://revistaseletronicas.pucrs.br/ojs/index.php/revistafamecos/article/view File/6314/4589. Agosto.

Lévy, P. (1993) As tecnologias da inteligência: o futuro do pensamento na era da informática. Trad. Carlos Irineu da Costa. São Paulo: Editora 34.

Marczal, D. and Direne, A. (2012) "FARMA: Uma ferramenta de autoria para objetos de aprendizagem de conceitos matemáticos."Anais do $23^{\circ}$ Simpósio Brasileiro de 
Informática na Educação (SBIE 2012), ISSN 2316-6533 Rio de Janeiro, 26-30 de Novembro. http://www.lbd.dcc.ufmg.br/colecoes/sbie/2012/0028.pdf. Agosto.

Nóvoa, A. (org.). (1998) As organizações escolares em análise. Lisboa: Nova Enciclopédia.

Pozo, M. D. (2012) Como trabalhar com notebooks em sala de aula: o aprendizado baseado em problemas e projetos de compreensão. Barba, C. and Capella, S. (Org.). Computadores em sala de aula: métodos e usos. Porto Alegre: Penso.

Rodrigues, M. de F. and Kuenzer, A. Z. (2007) As diretrizes curriculares para o curso de pedagogia: uma expressão da epistemologia da prática. Revista: Olhar de professor. Universidade Estadual de Ponta Grossa: Ponta Grossa, n. 10, páginas 35-62.

Santaella, L. (2010) A aprendizagem ubíqua substitui a educação formal? RECeTRevista de Computação e Tecnologia da PUCSP- Interatividade, tecnologias interativas e aprendizagem .v. 2, n. 1. http://revistas.pucsp.br/index.php/ReCET. Agosto.

Santaella, L. (2007) Linguagens líquidas na era da mobilidade. São Paulo: Paulus.

Schlemmer, E.; Saccol, A. Z.; Barbosa, J. and Reinhard, N. (2007) M-learning ou aprendizagem com mobilidade: casos no contexto brasileiro. ABED. http://www.abed.org.br/congresso2007/tc/552007112411PM.pdf. Agosto.

Sharples, M.; Taylor, J. and Vavoula, G. (2005) Towards a theory of mobile learning. proceedings of mLearn, 2005 Conference, Cape Town.

Sharples, M. (2003) Disruptive Devices: mobile technology for conversational learning. International Journal of Continuing Engineering Education and Lifelong Learning, n.12, páginas 504-52.

Schmidt , M.A and Garcia, T.M.B. (2008) História e educação: diálogos em construção. In: Schmidt, M.A; Garcia, T.M.B.; Horn, G. (org.). Diálogos e perspectivas de investigação. Ijuí: UNIJUÍ.

Tikhomirov, O. K. (1981) “The Psychological consequences of computerization.” In: Wertsch, J.V. (Ed.) The concept of activity in soviet psychology. New York: M.E.Sharpe. Inc. páginas 256-278

Veiga Neto, A. (1997) Currículo e interdisciplinaridade. In: Moreira, A. F. B. Currículo questões atuais. Campinas: Papirus.

Veiga. I. P. A. (1996) A prática pedagógica do professor de didática. 2. ed. Campinas: Papirus.

Vincent, G; Lahire, B. and Thin, d. (2001). Sobre a história e a teoria da forma escolar. Educação em Revista. Belo Horizonte, n. 33 . páginas 7-47. http://educa.fcc.org.br/pdf/edur/n33/n33a02.pdf. Agosto. 